\title{
GESTÃO DO ACERVO DO ARQUITETO EDUARDO KNEESE DE MELLO:

\author{
RELATO DO TRATAMENTO ORGANIZACIONAL DA \\ COLEÇÃO ICONOGRÁFICA
}

ADEMIR PEREIRA DOS SANTOS, UNIVERSIDADE DE TAUBATÉ, TAUBATÉ, SÃO PAULO, SÃO PAULO, BRASIL Graduado em Arquitetura e Urbanismo pela Universidade Estadual de Londrina em 1986, mestre em História pela Universidade Estadual de São Paulo em 1992 e doutor em Arquitetura e Urbanismo pela Universidade de São Paulo.

E-mail:dmi@hotmail.com

ELISA HORTA DA SILVA, UNIVERSIDADE DE SÃO PAULO, SÃO PAULO, SÃO PAULO, BRASIL.

Graduada em Arquitetura e Urbanismo pelo Centro Universitário Belas Artes de São Paulo em 2016. E-mail: elisa.horta@hotmail.com

IZADORA ARAÚJO AMARAL, CENTRO UNIVERSITÁRIO BELAS ARTES, SÃO PAULO, SÃO PAULO, BRASIL. Graduada em Arquitetura e Urbanismo pela Universidade Estadual de Maringá em 2013 e especialista em Museologia, Colecionismo e Curadoria pelo Centro Universitário Belas Artes de São Paulo em 2015.

E-mail: izadora_amaral@hotmail.com

DOI

http://dx.doi.org/10.11606/issn.1980-4466.v0i24p134-161 


\section{GESTÃO DO ACERVO DO ARQUITETO EDUARDO KNEESE DE MELLO:RELATO DO TRATAMENTO ORGANIZACIONAL DA COLEÇÃO ICONOGRÁFICA \\ ADEMIR PEREIRA DOS SANTOS, ELISA HORTA DA SILVA, IZADORA ARAÚJO AMARAL}

\section{RESUMO}

O presente trabalho pauta-se no relato do processo de organização e catalogação primária da seção iconográfica do acervo do arquiteto Eduardo Kneese de Mello (1906-1994), realizado no ano de 2015, atualmente integrado à biblioteca do Centro Universitário Belas Artes de São Paulo. O fundo, produzido em vida pelo arquiteto, recuperou força no ano de 2006, com sua proficuidade anunciada pelo Dr. Ademir Pereira dos Santos como fonte de pesquisa, estimulando o início de diferentes manejos. Após a elucidação acerca da trajetória institucional deste material, demonstra-se aqui uma produção orientada por inquietações díspares aos trabalhos anteriores, objetivadas pela correlação da porção mais significativa do acervo, os slides, com as demais espécies documentais que compõem o conjunto do acervo. Seguinte à compreensão dos escopos que sucederam o vasto material constituinte do fundo, demonstra-se a metodologia empregada para tratamento, diagnóstico e estruturação do catálogo, assim como sua importância como base informacional, através da qual se constituiu um panorama visual e quantitativo com o auxílio e gerenciamento de tabelas descritivas, gráficos percentuais de diferentes análises e a elaboração de mapas com roteiros ilustrativos que proporcionaram a exatidão geográfica de seu conhecimento e dos testemunhos históricos. A especulação das camadas existentes possibilitou o início da confirmação de informações publicadas sobre o arquiteto e mais uma complementação de sua biografia, com o conhecimento total de suas viagens. Considerou-se como função primordial a caracterização panorâmica do conteúdo do acervo, até então desconhecida, acabando-se por evidenciar futuras problemáticas a serem enfrentadas, potencialidades e ações e intervenções urgentes e primordiais à sobrevivência do fundo.

PALAVRAS-CHAVE

Acervo fotográfico. Diapositivo. História da arquitetura - Brasil. 


\title{
MANAGEMENT OF THE ARCHITECT EDUARDO KNEESE DE MELLO'S ARTISTIC HERITAGE: REPORT ON THE ORGANIZATIONAL TREATMENT OF THE ICONOGRAPHIC COLLECTION
}

\author{
ADEMIR PEREIRA DOS SANTOS, ELISA HORTA DA SILVA, IZADORA ARAÚJO AMARAL
}

\section{ABSTRACT}

Conducted in 2015, this research focuses on the report of the process of organization and primary cataloguing of the iconographical section of architect Eduardo Kneese de Mello's (1906-1994) collection, currently integrated into the library of the University Center of Fine Arts of São Paulo. The collection, produced by the architect throughout his life, regained strength in 2006, as Professor Ademir Pereira dos Santos found in his work a source of research, stimulating different ways of handling it. After the elucidation on the institutional trajectory of this material, a production guided by concerns that are different from those of previous researches, objectified by the coexisting relations between the most significant part of the collection - the slides - and the other documentary species that make it up, is shown here. Following the comprehension of the scopes that succeeded the vast constituent material of the collection, the methodology applied in the treatment, diagnosis and structuring of the catalogue will be shown, as well as its importance as informational basis, through which a visual and quantitative outlook was built with the support and management of descriptive charts, percental graphics of different analyses and the elaboration of maps with illustrated scripts that provided the geographical accuracy of his knowledge and historical testimonies. The speculation of the existent layers enabled the beginning of the confirmation of the published information about the architect and a further complementation of his biography, with the complete knowledge about his travels. The panoramic characterization of the collection's content, unknown up until that point, was considered as the main objective, evidencing the problems to be faced in the future, as well as the potentialities and actions deemed as urgent and primordial to its survival.

\section{KEYWORDS}

Photographic collection. Slide. Architecture history - Brasil. 


\section{INTRODUÇÃO}

Este artigo trata do relato de organização do acervo pessoal do arquiteto Eduardo Kneese de Mello (1906-1994) para o Trabalho Final de Graduação do curso de Arquitetura e Urbanismo denominado Registros de um arquiteto peregrino: identificação e organização do acervo fotográfico de Eduardo Kneese de Mello e Trabalho de Conclusão de Curso do curso de Pós-Graduação em Museologia, Colecionismo e Curadoria, denominado Gestão do Acervo Eduardo Kneese de Mello: reflexões para fundamentação do tratamento organizacional da coleção iconográfica.

Iniciado em abril de 2015, o presente tratamento ateve-se a uma metodologia organizacional baseada nos fundamentos de que acervos constituídos ao longo da trajetória de um indivíduo, abarcando tanto aspectos profissionais quanto pessoais, podem atuar como testemunha de fatos e aspirações que, entrelaçados, contribuem para a preservação e difusão de suas memórias. Para tanto, devem receber um tratamento organizacional pautado em uma metodologia que considere também as especificidades de seu titular.

Portanto, a metodologia criada ateve-se a substancializar a preservação da organicidade característica do acervo e a produzir um instrumento de pesquisa. Tal como a conservação de seus constituintes. Ainda como finalidade, espera-se que este estudo possibilite um planejamento de adequação das infraestruturas necessárias a sua manutenção e acondicionamento. 
A contagem dos slides, outra atividade realizada, se demonstrará na produção de gráficos percentuais e quantitativos.

Mesmo contendo grandes e importantes testemunhos da História da Arquitetura Brasileira e Mundial do século XX, o acervo de Kneese de Mello vem recebendo pouco incentivo e importância em relação a sua organização e acesso público. Seu reconhecimento é de extrema diminuta, principalmente quando aferido a seus contemporâneos, como exemplo de Vilanova Artigas, Rino Levi, Oswaldo Bratke, entre outros.

Sobrepujando o arranjo geral, tivera-se como intento a elaboração de cronologias acerca da vida tanto profissional quanto pessoal do arquiteto, de modo a proporcionar uma melhor interpretação e complementação biográfica, quando necessária. Outra investigação coube a espacialização em mapas das andanças realizadas, por meio da identificação da localização original dos temas fotografados, assim como suas datas de execução. Todas as análises contam com a complementação e comparação dos fatos materializados com os presentes documentos e cartas de agradecimentos no domínio da biblioteca. Assim como os slides, os assuntos confirmados nos documentos e cartas serão catalogados e arquivados igualmente no banco de dados da pesquisa. De modo geral, buscou-se respeitar as características dos agrupamentos e das sequências elaboradas pelo arquiteto, de modo a repetir a estrutura administrativa e as atividades exercidas pela entidade produtora.

\section{A MATERIALIZAÇÃO DO LEGADO DE KNEESE DE MELLO}

Eduardo Kneese de Mello nasceu em 1906 e formou-se engenheiro-arquiteto em 1931, pelo colégio do Mackenzie. Tanto presenciou como partilhou as inquietudes e os rompimentos ideológicos que convulsionaram as artes na primeira metade do século XX. A arquitetura brasileira, em meados da década de 1940, também esquadrinhava seu processo de emancipação da linguagem historicista europeia. Neste momento, já em declínio, os edifícios, denominados de ecléticos tardios, reproduziam uma miscelânea de referências a estilos consagrados, como o neoclássico e o gótico, que compuseram, em abundância, as suas primeiras produções projetuais da década de 1930, seguindo preceitos da escola de Beaux Arts. Nas palavras do próprio Kneese de Mello, estes eram adotados servindo ao gosto da clientela, no seu caso, formada pela elite paulistana. 
Após o início da década de 1940, converteu-se ao modernismo e iniciou sua peregrinação frente à militância do movimento moderno e seu ideário, com produções arquitetônicas destinadas a habitações coletivas, culminando, no final da década de 1950, na colaboração para a construção da cidade de Brasília. Nesse momento, Kneese de Mello fora convertido ao movimento modernista. Como conclui Regino (p. 77, 2011), "[...] para Kneese, tornar-se moderno foi questionar-se qual seria a função social do arquiteto e o real significado da arquitetura [...]". Em 1964, tornou-se conhecido como pioneiro na produção de uma Arquitetura Industrializada no Brasil, tendo como marco o Conjunto Residencial dos estudantes da Universidade de São Paulo (CRUSP), como mostra a imagem digitalizada do acervo, na Figura 1.

Apresentar Kneese de Mello por esta transição de paradigmas, que vivenciou em conjunto com outros arquitetos de sua geração, é pertinente, pois ela se reflete profundamente em toda sua trajetória profissional. Atuando em diversas entidades, como o Instituto de Arquitetos do Brasil (IAB) e o Instituto do Patrimônio Histórico e Artístico Nacional (Iphan), o arquiteto militou para a consolidação das atribuições de sua profissão, assim como pela difusão dos preceitos modernistas no país. Foi também como incansável pesquisador e professor nas cadeiras de Arquitetura Brasileira e História da Urbanização em escolas como Universidade de São Paulo (USP), Belas Artes, Mackenzie, Universidade Brás Cubas e na atual Universidade de Guarulhos (UNG), que suas convicções foram mais uma vez afirmadas e irradiadas.

FIGURA 1

Conjunto Residencial dos Estudantes (CRUSP) - São Paulo-SP. Digitalização de imagem de diapositivo. Fonte: Acervo Eduardo Knesse de Mello.

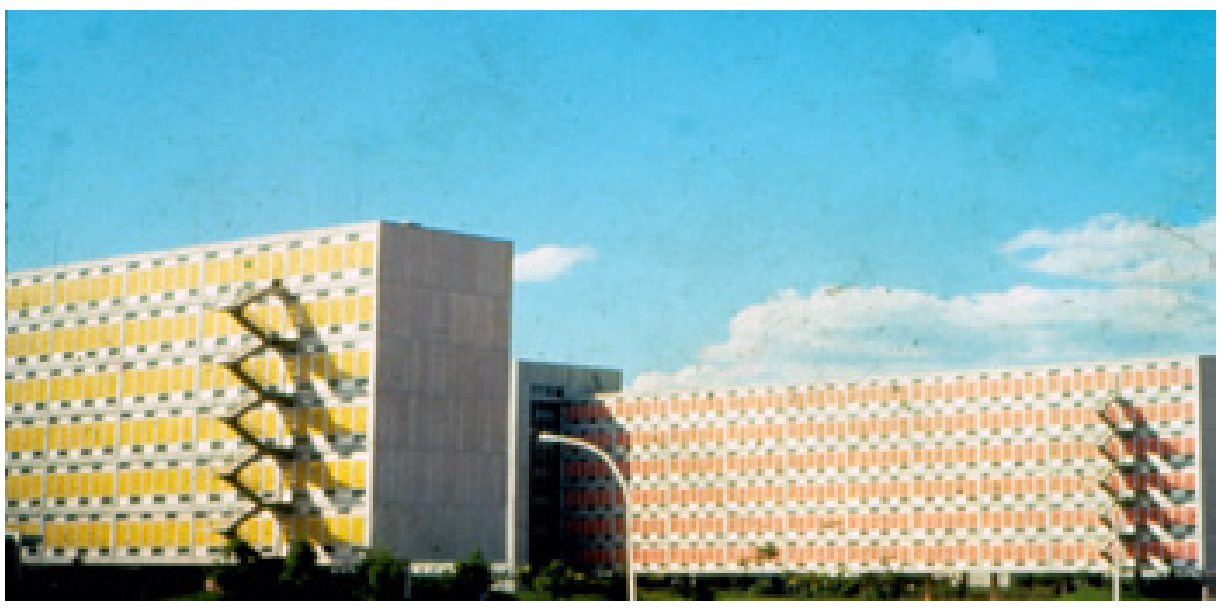


Como representante das instituições em que atuou, Kneese percorreu as cinco regiões brasileiras e uma série de outros países, ora em comitês de organização, ora como palestrante convidado. Seu desempenho como articulador diplomático proporcionou que testemunhasse e investigasse com mais propriedade as obras arquitetônicas que ocupavam suas falas e textos. Para tanto, valia-se dos registros fotográficos em filmes diapositivos, posteriormente emoldurados para serem projetados, como instrumento para ampliar e estender a fruição deste contato.

Portanto, seu legado se materializou não somente em expressivos edifícios modernistas, como também nos livros, revistas, documentos, correspondências, peças gráficas, fotografias em papel e 11.090 imagens em slides (diapositivos) que preservou e que desvelam uma carreira profícua. Atualmente, grande parte do material que compõe o acervo pessoal Eduardo Kneese de Mello (EKM) encontra-se integrado à biblioteca do Centro Universitário Belas Artes de São Paulo.

\section{A TRAJETÓRIA INSTITUCIONALIZADA DO ACERVO EDUARDO KNEESE DE MELLO}

Sabe-se que o processo de aquisição do acervo de Kneese de Mello ocorreu em duas etapas. Em 1994, após o falecimento do arquiteto, o numeroso conjunto de slides e os livros que compunham a biblioteca do titular do acervo foram comprados em negociação com familiares pelo Centro Universitário Belas Artes, instituição de guarda na qual o arquiteto lecionou a partir da década de 1980. E posteriormente, no início dos anos 2000, a vasta gama de documentos em papel que ainda se encontrava sob domínio da família, por meio de doação. Este montante textual é composto por escritos teóricos de Kneese, telegramas, cartas, diplomas, certificados, recortes de artigos de periódicos e documentos originais. Ademais, uma parcela do acervo foi direcionada à tutela da Faculdade de Arquitetura e Urbanismo da USP, em especial as peças gráficas, como plantas de seus projetos.

Os tratamentos dedicados ao acervo seguiram isolados entre si, de acordo com a espécie e formato documental, com um enfoque maior na preservação bibliográfica e iconográfica, desassistindo outros documentos integrantes do acervo. Os livros receberam os reparos necessários e foram catalogados respeitando sua unicidade enquanto acervo bibliográfico 
pessoal e incorporados ao sistema de catalogação da biblioteca, enquanto as fotografias em papel foram organizadas e acondicionadas em pastas com identificação.

A coleção de slides que integra o acervo é composta por 11.090 diapositivos cromogêneos em suporte de acetato de celulose, exceto por uma diminuta parte em suporte de vidro. O formato do filme é $24 \times 36 \mathrm{~mm}$, montado em moldura (caixilho) de $5 \times 5 \mathrm{~cm}$. Ao ingressar na instituição, estavam acondicionados em pastas e pequenas caixas de plástico e papelão e apresentavam em geral bom estado de conservação. No ano de 2007, empreendeu-se um processo de identificação e organização deste material, realizado pelos professores Ademir Pereira dos Santos e Aline Nassaralla Regino. Outras pesquisas em torno do acervo resultaram, no ano de 2005, na publicação do livro Arquitetura, atribuição do arquiteto como comemoração ao centenário de Kneese de Mello. E por fim, um projeto para construção de uma página na internet sobre o acervo permitiu, em 2011, a digitalização de uma parcela da coleção de slides. Com início em abril de 2015, sob a orientação do professor do curso de arquitetura da instituição Ademir Pereira dos Santos, se desenvolveu o atual tratamento organizacional do acervo EKM, apresentado a seguir.

\section{OS DIAPOSITIVOS (SLIDES)}

Um acervo pessoal é definido como a reunião de materiais produtos das atividades exercidas em vida por uma determinada pessoa. Neste sentido, as informações biográficas, assim como as correlações entre os demais documentos que compõem o acervo, são instrumentos para a contextualização das imagens, colaborando para a construção de sentidos. A partir desse cruzamento de referências, procura-se desvendar as intenções voluntárias e involuntárias que fundamentam a produção das imagens.

\footnotetext{
Do ponto de vista do tratamento arquivístico, esse é o momento mais significativo da vida do documento, aquele capaz de lançar luz sobre as razões e os sentidos dos registros, das relações desses com seus congêneres, e do conjunto com o responsável pela sua existência: o titular do arquivo. [...] esses vínculos, que supostamente são mais evidentes enquanto o arquivo está sendo forjado, frequentemente precisam ser restabelecidos, reconstruídos (LACERDA, 2012, p. 285).
} 


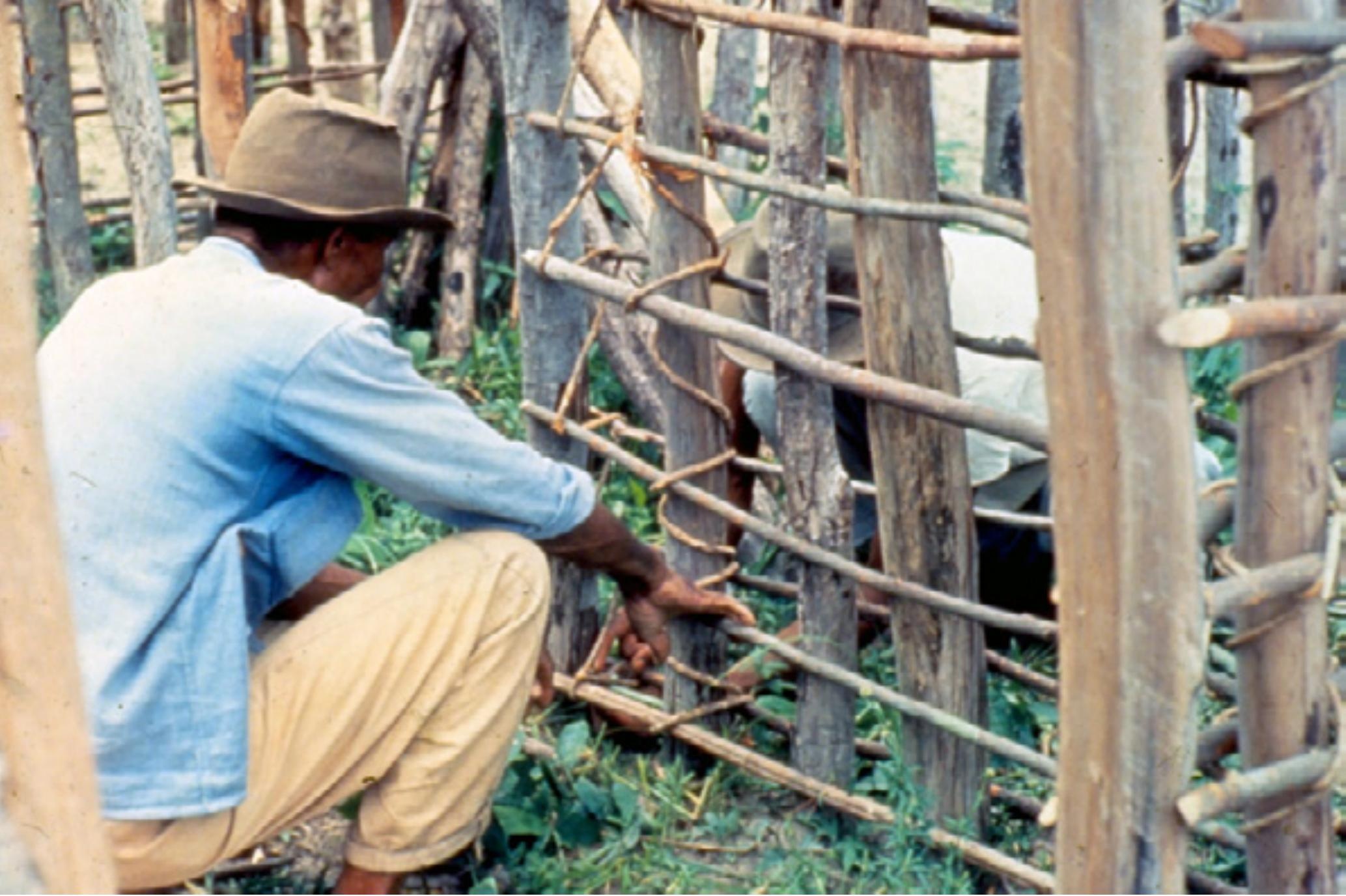

FIGURA 2

Caboclo montando taipa de mão Gaibu-PE. Digitalização de imagem de diapositivo. Fonte: Acervo Eduardo Knesse de Mello.

A coleção de Kneese de Mello contempla, entre suas imagens, realizadas durante as décadas de 1940 a 1990, as igrejas jesuítas de Salvador, o barroco mineiro do período colonial, o neoclássico da capital carioca despontado no império e a catedral modernista de Brasília. Retrata as fazendas que guardam as antigas casas senhoriais dos engenhos e também os casebres construídos pelos bandeirantes de São Paulo. Ainda reúne o registro de grande parte das técnicas construtivas empregadas no Brasil durante o século 20: pau a pique, taipa de pilão, da alvenaria de pedra às peças pré-fabricadas em concreto, as inovações das estruturas metálicas e a plasticidade do concreto armado.

Os entremeios das visitas aos objetos arquitetônicos também se revelam na coleção. A companhia assídua de sua esposa, os estudantes em aula de campo, o quórum das plateias dos congressos, a convivência com os colegas de profissão e a função hospitaleira de receber ilustres arquitetos estrangeiros em visita ao Brasil estão presentes. 


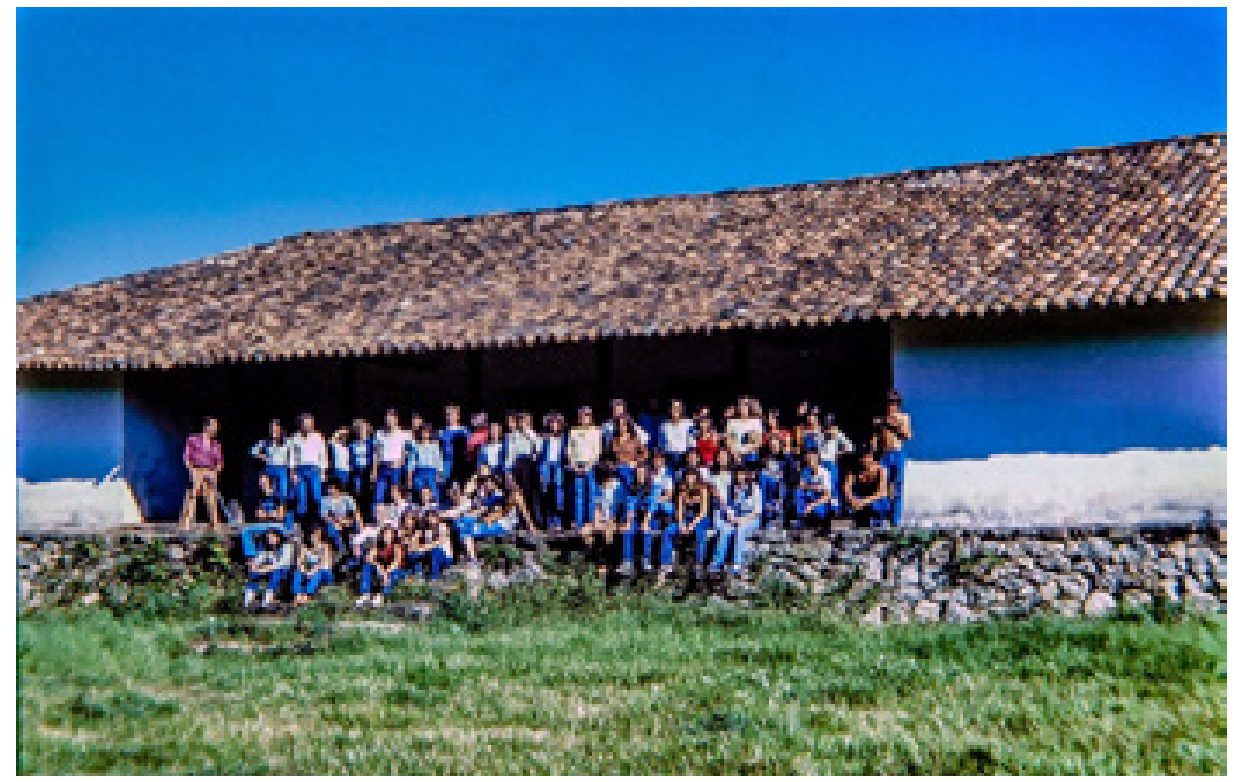

Santos (2009, p. 6), em artigo que discorre sobre a prática dos registros fotográficos durante as viagens de Kneese de Mello, conclui que se trata de um "quase método". É claramente distinguível que o arquiteto se preocupava com a formação de séries temáticas ao fotografar, assim, sendo raras as imagens isentas de pares. Também se preocupava em proporcionar uma leitura abrangente de seu objeto, contextualizando-o espacialmente. A insistência em múltiplos enquadramentos da mesma cena demonstra a posterior intenção editorial, possivelmente advinda de seu envolvimento durante anos com a publicação da revista dedicada à arquitetura, a Acrópole.

A produção e extroversão do conteúdo destes diapositivos tinham como finalidade principal funcionar como instrumento didático para as palestras e aulas de história da arquitetura ministradas pelo professor durante grande parte de sua vida. Percebe-se que a intenção que estimula a constituição desta coleção não está de fato no objeto tridimensional - o diapositivo - e sim nas informações contidas nas imagens reveladas quando expostas à luz das lâmpadas dos projetores. Como o desejo que move muitos colecionadores a adquirir a todo custo o objeto raro e inestimável que irá preencher a lacuna de sua coleção, o anseio pela completude de tudo que permeia a arquitetura parece guiá-lo. Conformam-se como uma 
coletânea de referências do universo arquitetônico, as quais se subdividem em diversas categorias.

\footnotetext{
[...] o colecionador consegue lançar um olhar incomparável sobre o objeto, um olhar que vê mais e enxerga diferentes coisas do que o olhar do proprietário profano [...]. Para o colecionador, o mundo está presente em cada um de seus objetos e, ademais, de modo organizado. [...] Basta que nos lembremos do quão importante é para o colecionador não só o objeto, mas também todo o passado deste [...] (BENJAMIN, 2007, p. 241).
}

A sobreposição entre o ato de reunir objetos que contêm temas que buscam abranger de forma integral o campo da arquitetura e a função didática em que o seu produtor se pautou desvela outra amplitude de significações para este acervo agora institucionalizado: uma coleção de referências. "Colecionar é um fenômeno primevo do estudo: o estudante coleciona saber" (BENJAMIN, 2007, p. 245).

A potencialidade de seu acervo foi identificada pelo próprio Kneese de Mello, enquanto professor no ano de 1983, quando realizou uma compilação de seus slides para ilustrar um conjunto de textos que escreveu resgatando a origem da arquitetura brasileira até a produção contemporânea. Reunidos em belas caixas de madeira, intituladas A Evolução da Arquitetura no Brasil, foram distribuídas em todo país pelo Ministério da Educação no Programa Integrado de Melhoria do Ensino de Graduação em Arquitetura (PIMEG), em parceria com a Universidade Federal do Rio Grande do Sul (UFRGS).

\subsection{Organização}

A primeira etapa organizacional estruturou-se a partir da identificação da origem e dos assuntos presentes - visualização, descrição e organização. Todos os slides encontram-se armazenados fora dos padrões ideais de arquivística, porém, poucos são os que apresentam estado de conservação ruim e precisam de trabalho mais elaborado de restauro - muitos dos quais já haviam sido identificados pelo autor para restauro - , que deverão ser realizados por profissionais capacitados da biblioteca ou empresas terceirizadas.

Mesmo após diversas tentativas de ordenação dos slides, identificou-se a existência de diversas caixas com temas misturados. Baseando-se no conhecimento de que os slides eram utilizados em palestras e aulas, 
fundamentaram-se duas hipóteses: a primeira de que as caixas deviam estar em pleno uso no ano de seu falecimento, tendo sua desorganização justificada por falta de tempo, e a de que foram descaracterizadas com o mau manuseio e cuidado, por parte da instituição proprietária, desde sua aquisição. Kneese compunha séries selecionadas especificamente para cada aula com slides originários de diversas caixas e pastas: "[...] solicitamos vênia para sugerir que essas aulas, confiadas acertadamente à esclarecida competência de V. Sa. sejam acompanhadas de ilustrações e se revistam de caráter essencialmente didático. (...)"1

Algumas caixas, quando abertas, apresentam uma única imagem desconexa. Essas imagens, quando identificadas, são separadas e reintegradas ao seu grupo de origem. O percentual de slides sem grupo ainda se mantém grande e agrupado em uma caixa denominada "Desconhecidos", que posteriormente receberá devidos cuidados. A finalização da catalogação facilitará a identificação dos grupos de origem desses slides "desconhecidos".

Todos os 11.090 slides foram visualizados e quantificados, dentre os quais, $85 \%$ possuem localização em suas descrições.

\subsection{Estado de conservação}

Mesmo sem acondicionamento apropriado, a grande maioria dos slides apresenta bom estado, tanto em questão de aparência e condição física como na preservação de suas cores. Poucos são os slides que necessitam de restauração imediata, dentre os quais, alguns pouquíssimos tiveram sua emulsão parcial ou totalmente danificada. Todos os slides necessitam de higienização.

Encontram-se armazenados, em sua grande maioria, em caixas plásticas, algumas sem tampa ou até mesmo quebradas. E outra parte, separada em sacos plásticos, necessitando urgente aquisição de materiais adequados para ação de acondicionamento e interrupção do derretimento de sua emulsão. Os slides separados por elásticos tiveram os mesmos retirados, de modo a evitar danos permanentes com seu amolecimento.

1. Carta datada de 14 de março de 1963, enviada pela Comissão Municipal de Cultura da Prefeitura Municipal de Santos a Eduardo Kneese de Mello, referente à confirmação de duas referências sobre o tema "Arquitetura Brasileira", na série determinada "Arte Colonial Brasileira", promovida pela comissão. 


\subsection{Características}

Os diapositivos (slides) apresentam formato de $35 \mathrm{~mm}$, com suporte em acetato e molduras entre plástico, papel e uma única série emoldurada em vidro, com a colagem de papéis, na cor vermelha, por toda sua volta. Tratando-se de registros realizados durante o acontecimento do VIII Congresso Pan-americano de Arquitetos do México.

\section{O CATÁLOGO}

Refere-se à mais recente abordagem de gestão do acervo Eduardo Kneese de Mello, iniciada em abril de 2015, a qual busca dar continuidade a um minucioso processo de identificação e organização deste material realizado entre os anos de 2007 e 2009. Este foi concluído em âmbito físico e visou reconstituir a composição originária das séries produzidas pelo arquiteto durante suas viagens, estruturando-as em grandes grupos temáticos. Como fonte de informação, foram utilizadas as inscrições feitas pelo próprio autor nas molduras dos slides. Estas indicam informações como código da série, assunto, data e local onde as fotos foram tiradas, sendo raros os que apresentam concomitantemente todas estas informações.

A elaboração caminhou seguindo primordialmente da localização territorial na qual cada slide havia sido produzido. A escolha por preservar as origens geográficas dos slides como denominadoras dos grupos no quadro de arranjo deu-se pela grande presença de inscrições que indicavam os locais fotografados, feitas pelo próprio autor. Kneese mantinha o costume de anotar e especificar, nas molduras, os países e estados que visitava.

Como base, pesquisas e leituras biográficas foram realizadas, assim como a contextualização de seus contemporâneos, de forma a substanciar a compreensão do universo ilustrado no acervo. Formulou-se também um manual de preenchimento que esclarece a escolha dos termos utilizados aos futuros interessados na elaboração de trabalhos dentro do acervo, assim como o registro do controle de vocabulário, a fim de facilitar a produção de filtros de pesquisas, além da inserção de futuros dados. Sem especificar, independentemente do estado físico das imagens, os diapositivos (slides) nessa etapa do trabalho foram contados, identificados, datados e brevemente descritos em planilhas.

O quadro de arranjo seguiu como base vestígios temáticos separados pelo próprio arquiteto Eduardo Kneese de Mello. Ademais de as ordenações 
pré-existentes dos conjuntos, há sistemas de numeração e códigos inscritos nos suportes que auxiliam seu reconhecimento.

Foram recolhidas informações como o local do registro (país, estado ou cidade), seu estado de conservação (bom, regular ou ruim), data (ano), a presença ou não de inscrições originais (sim ou não), número de embalagem e localização dentro da biblioteca (CAIXA 1.1, 2.1), quantidade de slides por caixa, e descrições (as obras identificadas pelo autor e os lugares retratados). Ao campo observações, couberam detalhes pertinentes à identificação ou ao estado físico, de modo a enfatizar os que futuramente necessitarão de maior atenção.

Dentre as datas, apenas são listadas as que apresentam com clareza o período de produção do conjunto. Aos anos não sequenciais, as datas são separadas por conectivos "e" e vírgulas (ex. 1965,1970 e 1975) e quando se apresentam em períodos, com hífen entre o ano inicial e o final (ex. 19751985). Às datas completas, a ordenação por dia/mês/ano. Datas presentes na inscrição de apenas uma ou poucas molduras, que não representam o momento em que a série foi produzida, são inseridas no campo "Descrição" para que sejam posteriormente conectadas ao subtema a que se referem. Ex: Palácio do Itamaraty; Copacabana Palace em 1985; Candelária.

A hierarquização do arranjo responde à graduação de grupos, subgrupos e série de especificidade territorial. Ao grupo Nacional, corresponde como subgrupo um estado e ao Internacional seu subgrupo correspondente será um país. Definem-se como grupos:

1. Viagens Internacionais

2. Viagens Nacionais

3. Eventos

4. Reproduções e material didático

5. Personalidades

6. Obras EKM

Cada grupo, então, possui uma planilha separada com seus subgrupos e séries abertos em colunas. Para o preenchimento de todos os campos de dados, adotaram-se letras maiúsculas, e para as descrições e observações, letras minúsculas. Os grupos foram organizados em ordem alfabética seguida de uma ordem cronológica. A padronização 
final em ordem cronológica segue de forma a facilitar as futuras elaborações tanto na complementação da biografia do autor quanto no mapeamento de suas viagens.

FIGURA 4

Planilha elaborada para a produção do catálogo. Planilha viagens nacionais. Fonte: Elisa Horta e Izadora Amaral.

\begin{tabular}{|c|c|c|c|c|c|c|c|c|c|c|}
\hline 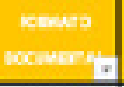 & Exrmo & atsentions & cate & Bats & artinest & 20 & 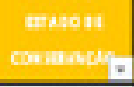 & 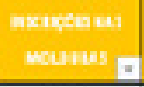 & $\sin \frac{1}{8}$ & Aasikes? \\
\hline taces & vactes wacous & acke & notrucs & as & $n$ & chocu: & $\cos$ & $n$ & $x$ & 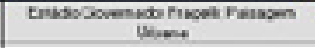 \\
\hline taces & nascess werowe & maceas & wetes & \$N4 & $\mathrm{N}$ & cheser: & esen & sen & क & 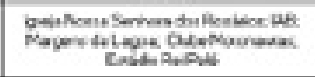 \\
\hline sers & vasstrs waroves & Lacras & nem & set & vข & cansis 1 & ects & $\operatorname{sen}$ & , & Ievextrud at Arcie \\
\hline suces & mases wrows & unceas & motes & $\infty$ & ven & chewat & $\cos$ & sen & s & 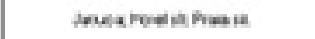 \\
\hline tases & macess wecous & maccas & $\begin{array}{l}\text { nescond } \\
\text { crocosc }\end{array}$ & SN & vo & coses: & ecs & $\operatorname{sen}$ & $\boldsymbol{x}$ & 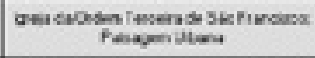 \\
\hline thens & mastak wacous & arcess: & nevtoo & ser & en & cososes & $\operatorname{ecc}$ & $\operatorname{sen}$ & ข & 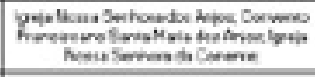 \\
\hline sues & vacetsworous & Aracceus & MANAS & 804 & 50 & Cance: 1 & $\mathrm{ECH}$ & sen & 7 & teans denvenes: \\
\hline ace & Macere wacows & $\operatorname{ccc} a n A$ & rocints & an- & $\mathbf{v e}$ & cances & DOH & 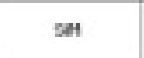 & , & 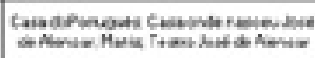 \\
\hline
\end{tabular}

FIGURA 5

Planilha elaborada para a produção do catálogo. Planilha viagens internacionais. Fonte: Elisa Horta e Izadora Amaral.

\begin{tabular}{|c|c|c|c|c|c|c|c|c|c|c|}
\hline at & 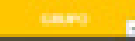 & $4=$ & $4=$ & 34 & 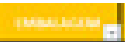 & 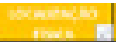 & 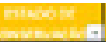 & 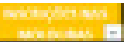 & 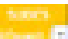 & cavestis \\
\hline $\sin$ & nester & 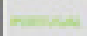 & 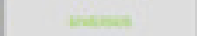 & $i=$ & 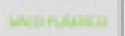 & 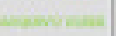 & $n=$ & sele & $=$ & \\
\hline nest & mavan & monote & 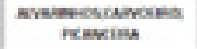 & 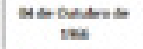 & ' & $\operatorname{casan} 12$ & $=m$ & $\omega$ & A & 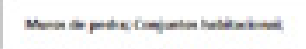 \\
\hline mex & monesion & nowne & uncosseresk & 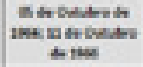 & - & $\operatorname{sen} 2 \mathrm{~s}$ & nom & 20 & * & 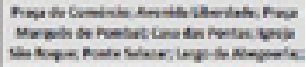 \\
\hline neen & nowasions & nomite & untiaconas & anovenos & - & $\operatorname{cosan} \mathrm{BS}$ & $=\infty$ & $\omega$ & 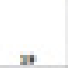 & 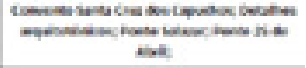 \\
\hline sen & mantom & nomove & mour rever & mingentan & : & $\cos a x$ & $\operatorname{mos}$ & $\omega$ & 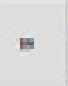 & 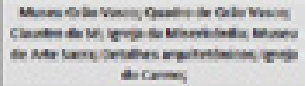 \\
\hline sees & nentors & nomote & 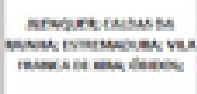 & not indist & "n & $\tan x$ & sim & $\omega$ & s & 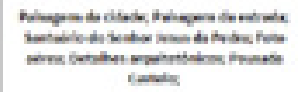 \\
\hline sees & mentors & nomber & 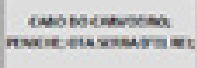 & 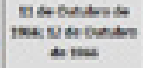 & $\mathrm{s}$ & $\cos x$ & $=\infty$ & $\omega$ & $\mathbf{m}$ & 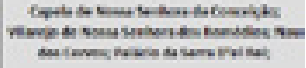 \\
\hline
\end{tabular}


FIGURA 6

Mesa de luz utilizada na identificação do conteúdo dos slides durante a descrição documental. Registro de imagem para o trabalho. Fonte: Elisa Horta e Izadora Amaral.

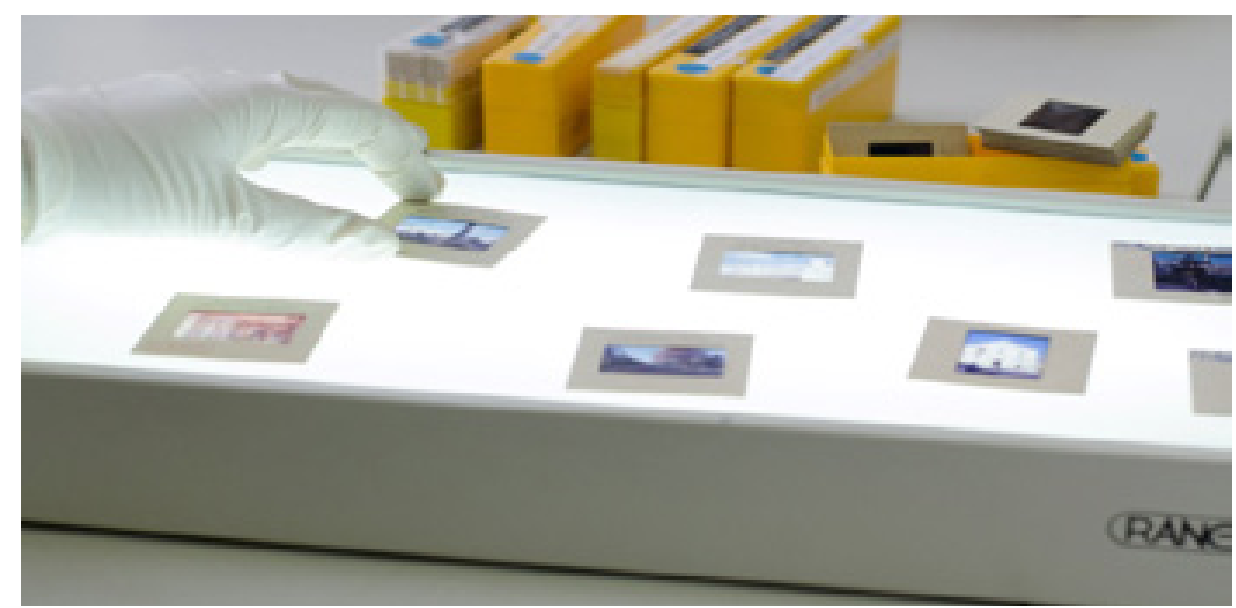

A visualização de todos os slides se deu por meio do manuseio individual de cada caixa plástica, auxiliada pelo uso de mesas de luzes e pela utilização de luvas descartáveis de látex. São caixas plásticas, de modo geral na cor amarela, que contemplam séries de no máximo 35 a 40 slides.

Ao concluir o preenchimento de todos os grupos, as planilhas finalizadas foram inseridas em uma planilha geral, de modo a possibilitar, pela primeira vez, uma visualização panorâmica do conteúdo do acervo. De modo complementar, um arquivo de auxílio e acompanhamento ao preenchimento foi produzido e recebeu o nome de Controle. Em uma aba denominada como Classificação, encontraram-se a hierarquização dos grupos, subgrupos e séries identificados. E na aba Catalogador e Data, após a finalização de cada subgrupo, a data e o responsável pelo preenchimento.

\section{QUANTIFICAÇÃO E RESULTADOS}

O processo de descrição documental fez evidenciar inquietações que até o momento passavam despercebidas, fazendo-se notar a emergência por obter conhecimento quantitativo acerca do conteúdo existente no acervo e a identificação, posterior, de suas potencialidades. A partir da perspectiva já empregada, criaram-se novas planilhas de dados, expandidas de acordo com as necessidades encontradas e do surgimento de novos assuntos. Para as obras de arquitetura, o preenchimento da planilha seguiu do recolhimento de dados, subdividindo primeiramente os slides de acordo com sua posição no espaço e 
tempo, ou seja, o local e o ano em que os registros foram produzidos e, num segundo momento, de acordo com seu estado de conservação e inserção histórica ou contemporânea (no caso, moderna) e sua linguagem arquitetônica - sendo a linguagem reconhecida e identificada por meio de pesquisas bibliográficas sobre a história do objeto, um edifício em sua grande maioria, selecionado. Ou daquelas identificadas pelo arquiteto em suas inscrições de moldura. Assim como as planilhas primeiramente elaboradas no trabalho, as novas subdividiram-se em "Nacionais" e "Internacionais" e, após a conclusão de seu preenchimento, compuseram uma unificada planilha de dados.

Contudo, durante o processo de preenchimento, a criação de outras colunas se fez necessária de acordo com a abordagem do autor, acarretando na abertura, na planilha de dados, de uma coluna para a determinação de "Assunto". Como exemplos de Assuntos determinados, tem-se:

1. Paisagem urbana: vistas aéreas e fotografias sem ponto focal direcionado

2. Projetos: registros da edificação de seus projetos arquitetônicos próprios ou em parceria com seus sócios

3. Arqueológico: entre ruínas e sítios arqueológicos

4. Reproduções: imagens de livros, documentos, projetos desenvolvidos para concursos, projetos e trabalhos de alunos

5. Personagens: fotografias de familiares e principalmente de arquitetos contemporâneos

6. Eventos: congressos fotografados

7. Memorial: monumentos comemorativos

8. Praças: a grande quantidade de praças históricas europeias visitadas

9. Fortalezas: estruturas militares arquitetônicas projetadas para guerras defensivas

10. Parques: parques municipais visitados

11. População local - Kneese costumava retratar muitos moradores das regiões de visitava

12. Detalhes: detalhes arquitetônicos e construtivos

13. Patrimônio: patrimônios históricos e artísticos brasileiros tombados pelo Instituto do Patrimônio Histórico e Artístico Nacional (Iphan) ou pelo Conselho de Defesa do Patrimônio Histórico (Condephaat).

14. Restauro: de modo a quantificar a quantidade de slides que necessitam de restauro. 
A quantificação dos assuntos encontrados na coleção de slides se concretizou como alicerce à conclusão, definitiva, do que o acervo trata de fato, e no fechamento de um banco de dados. A perspectiva ampliada das camadas existentes no acervo possibilitou o início da confirmação de informações publicadas sobre o arquiteto e a complementação das lacunas de sua biografia. $\mathrm{O}$ conhecimento total de suas viagens realizadas em vida se deu principalmente com a complementação da planilha a partir da consulta do passaporte de Wilma Quintanilha (esposa de Kneese, que esteve presente em todas as suas viagens) e dos documentos, cartas e certificações de participação em congresso e encontros nacionais e internacionais de arquitetos. Bem como a exatidão geográfica de seu conhecimento e dos testemunhos históricos arquitetônicos de seu século, por intermédio da elaboração de mapas.

\subsection{Gráficos}

Após o gerenciamento das tabelas, gráficos numéricos e percentuais em formatos de barras e "pizzas" foram produzidos e serviram à interpretação visual do número total de slides, dados e problemáticas que ainda deverão ser enfrentadas pelo acervo - como exemplo, os slides sem datas e os sem identificação de origem geográfica.

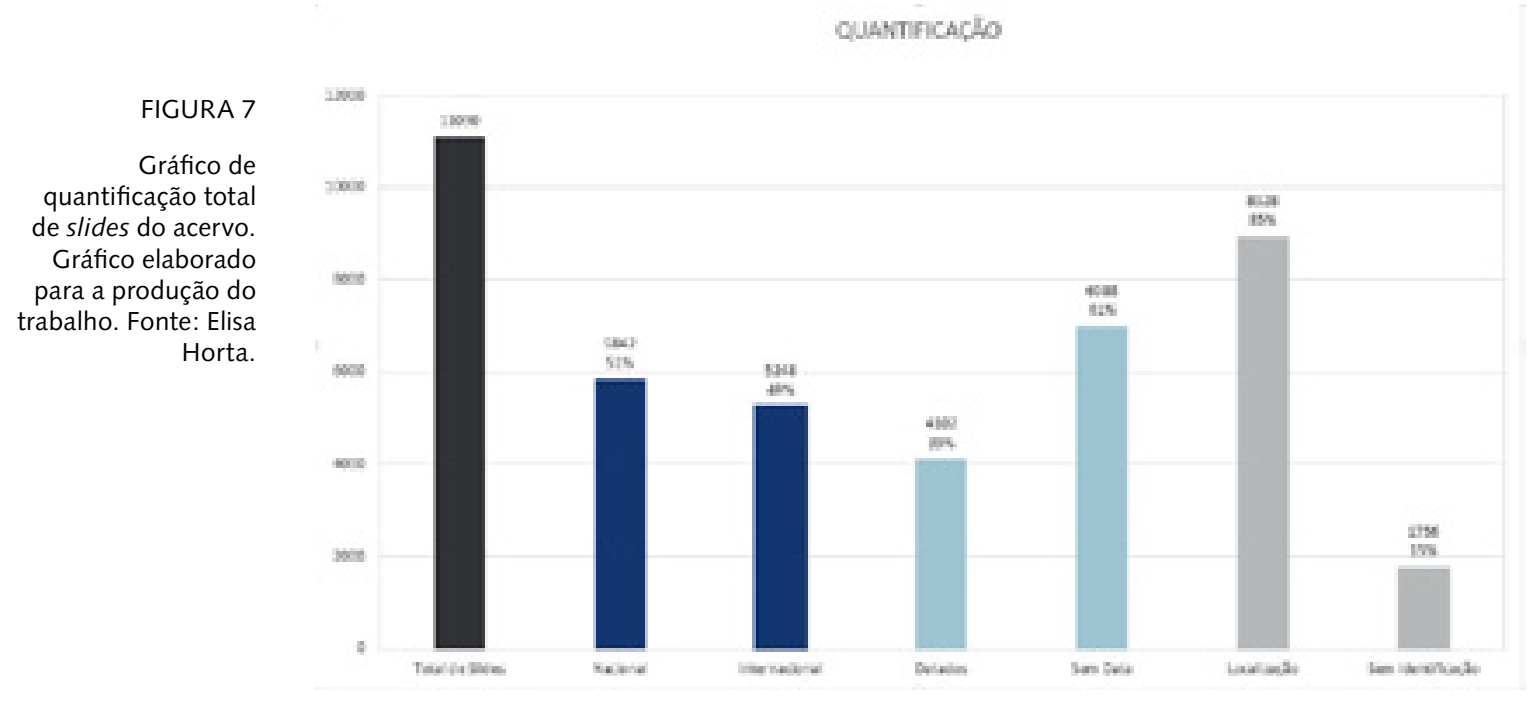


De maneira a apresentar a visão panorâmica dos percentuais de identificação dos assuntos, o gráfico apresentado traz a informação de quantos slides existem no acervo, de maneira exata, na barra de cor preta. Destes quais, do total de 11.090 slides, subdividem-se entre $85 \%$ os que possuem localização e $15 \%$ dos que não possuem, ilustrados nas barras de cor azul escuro. Seguindo a mesma lógica, fragmenta-se novamente os $100 \%$, entre as cenas produzidas em território brasileiro e as de cunho internacional, numa divisão quase que igualitária de $51 \%$ dos slides de testemunhos históricos nacionais e $49 \%$, internacionais, nas barras de cor azul claro. Na cor cinza, subdivide-se pela última vez o percentual de $39 \%$ dos slides identificados com inscrições, do arquiteto, com datas e os $61 \%$ encontram-se sem.

FIGURA 9

Gráfico de quantificação de slides por país. Gráfico elaborado para a produção do trabalho. Fonte: Elisa Horta.

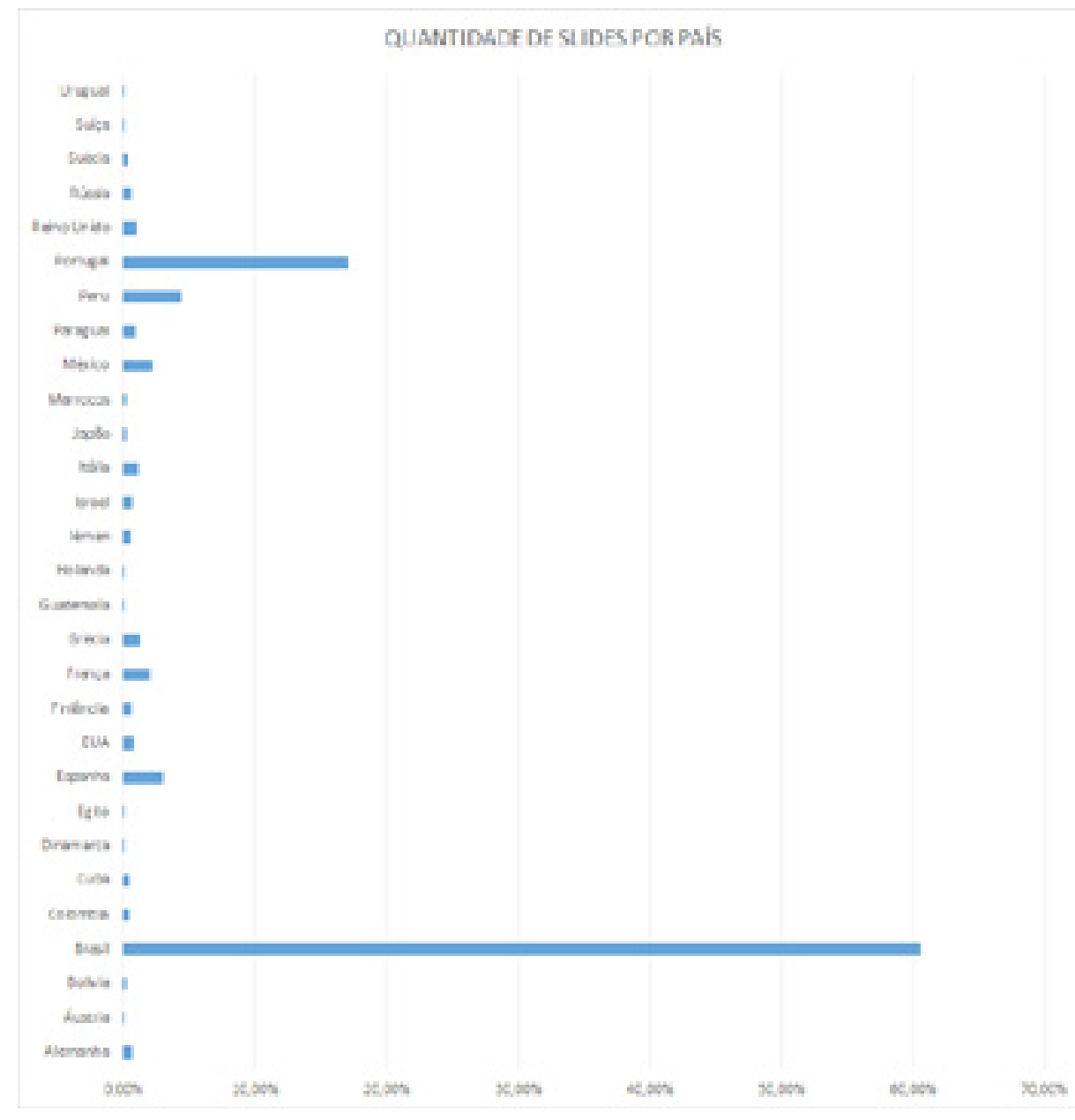


FIGURA 8

Gráfico de quantificação de slides por estado brasileiro.

Gráfico elaborado para a produção do trabalho. Fonte: Elisa Horta.

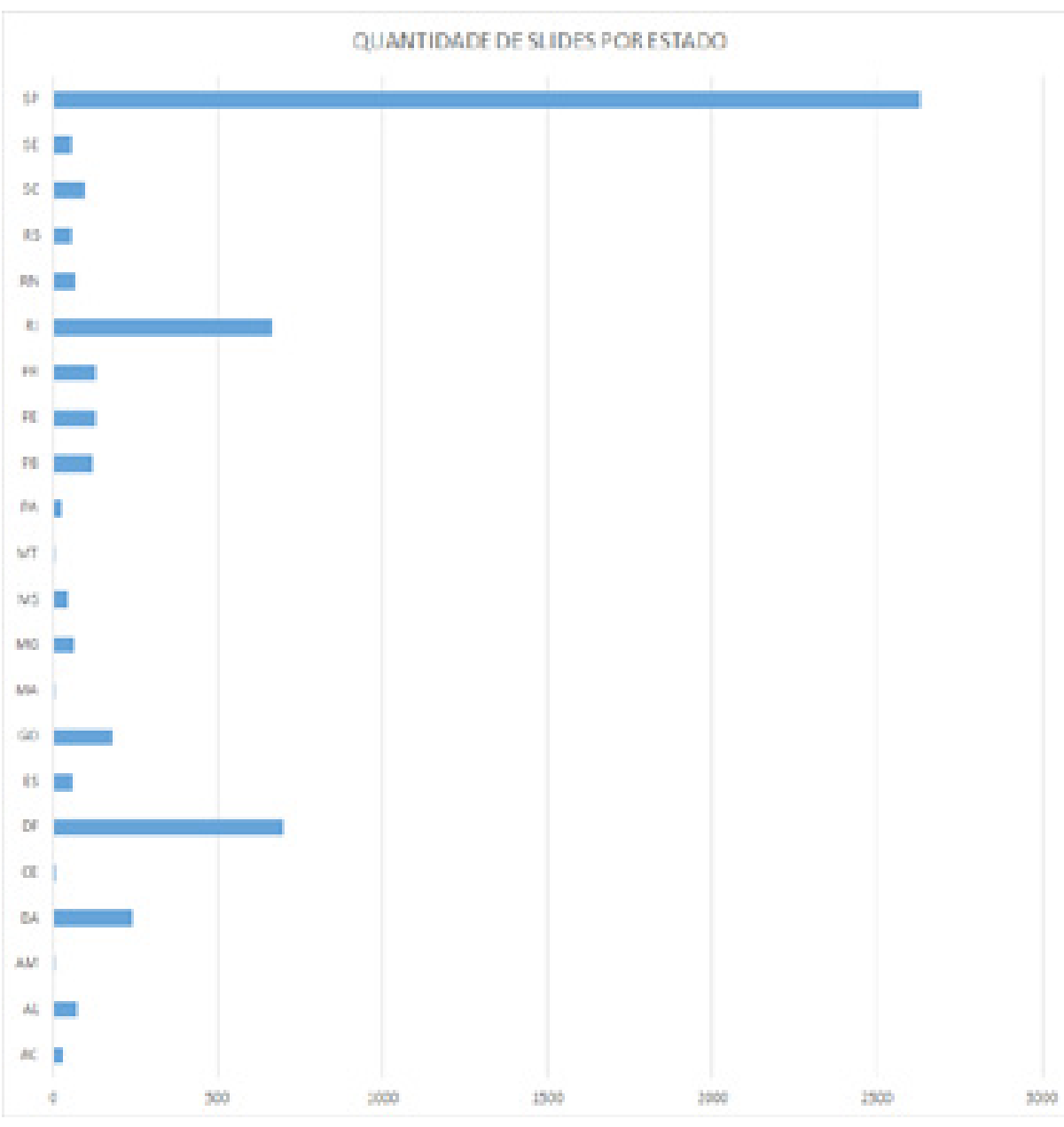

Os gráficos acima demonstram os países mais visitados, com destaque ao Brasil, Portugal, Peru e França. Dentro do Brasil, em maior quantidade de slides estão os estados de São Paulo, Distrito Federal, Rio de Janeiro e Bahia. Também vale destacar algumas informações retiradas de outros gráficos. Os anos que apresentam maior quantidade de registros - 1951 e 1966 - , por exemplo, quando Kneese obtém uma bolsa de estudos financiada pela Fundação Calouste Goubenkian e viaja durante alguns meses por toda a extensão de Portugal, registrando traços da herança mourisca na arquitetura portuguesa e, ao retornar, edita um livro, publicado pela Universidade de São Paulo, no qual estabelece características diretas e comprobatórias de que a dominação da Península Ibérica resultou não só na adaptação da 
arquitetura em Portugal como na construção de sua colônia (Brasil). E os anos de 1974 e 1975 evidenciam-se também, através de registros resultantes da peregrinação do arquiteto dentro do Brasil e com grande concentração nas regiões do Norte e Nordeste.

Outro ponto importante mensurado dentro do acervo refere-se às linguagens arquitetônicas que serviram de alvo para as lentes do arquiteto, deparando-se com registros brasileiros de linguagem bandeirista, colonial e barroca, pré-descritos pelo arquiteto em suas anotações de borda nas molduras dos slides, junto as suas localizações e datas. Dentre as vertentes internacionais - em grande maioria, europeias - além da fusão entre a arquitetura gótica, barroca e de influência ibero-muçulmana - manuelina, muito encontrada nas fotografias que produziu durante a sua estada em Portugal - encontram-se também linguagens do neoclássico, rococó, eclético e gótico. Denominações estabelecidas a partir de pesquisas bibliográficas sobre as histórias dos edifícios e monumentos retratados.

FIGURA 10

Gráfico de quantificação de slides por linguagem arquitetônica. Gráfico elaborado para a produção do trabalho. Fonte: Elisa Horta.

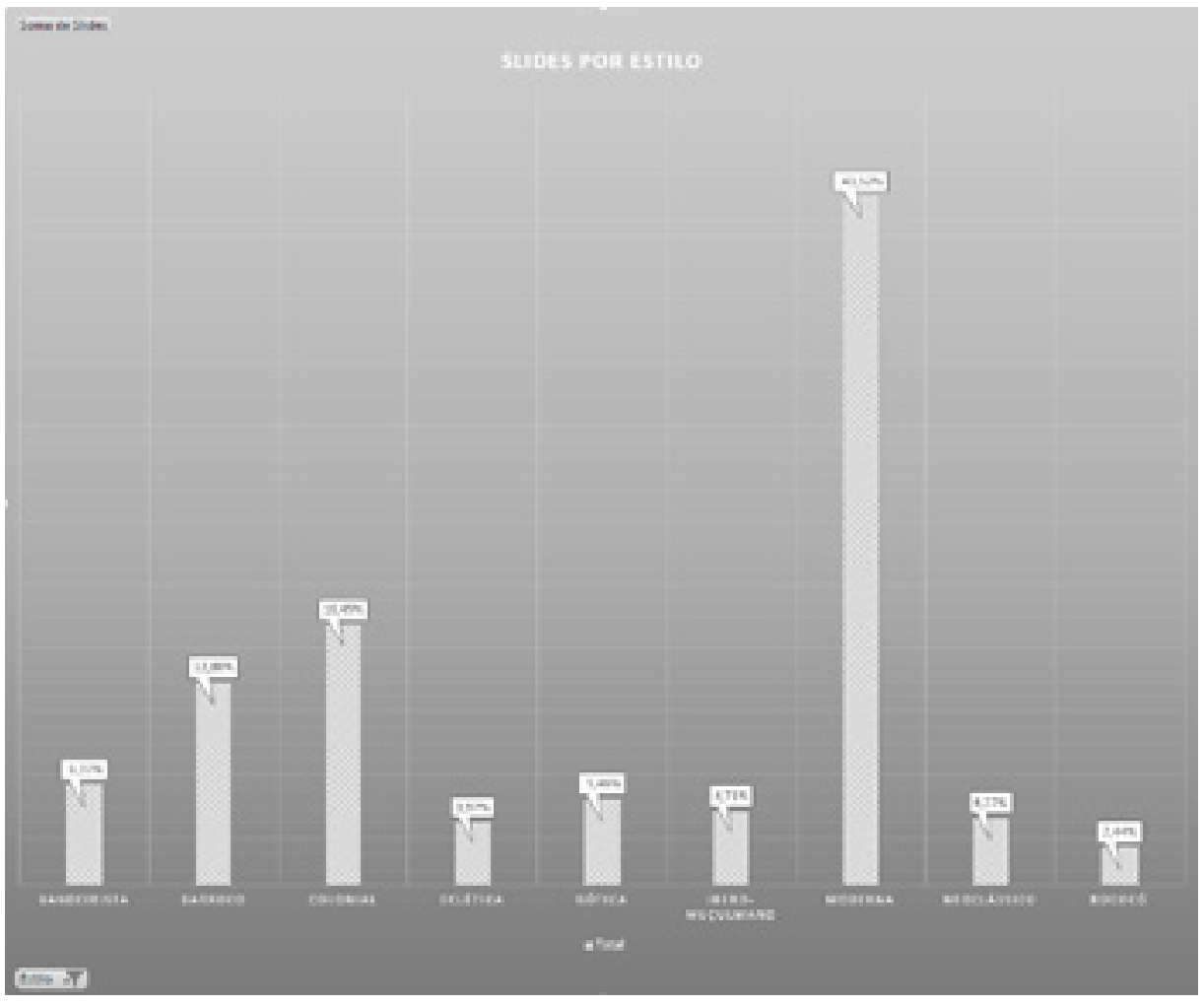


Concluindo, como destaque, a linguagem moderna, seguida da colonial, barroca, bandeirista e gótica.

Levando-se em conta os dados mais relevantes do interior dos registros, pode-se quantificar, de um modo geral, a presença de $70 \%$ de registros de valor histórico e $30 \%$ de retratos de seu tempo.

\subsection{Mapas}

Concomitante à produção dos gráficos e para ajudar a elucidação dos roteiros seguidos em vida por Eduardo Kneese de Mello, mapas-múndi ilustrativos foram elaborados para demonstrar a localização de suas maiores produções iconográficas e ilustrar seus caminhos percorrido, divididos em décadas, dando a oportunidade de observar caminhos seguidos a cada dez anos e os eventos em destaque. Como o mapa da década de 1960, ilustrado abaixo:

FIGURA 11

Países fotografados nas décadas de 1940 , 1950 e 1960, em mapa-múndi. Mapa elaborado para a produção do trabalho. Fonte: Elisa Horta.
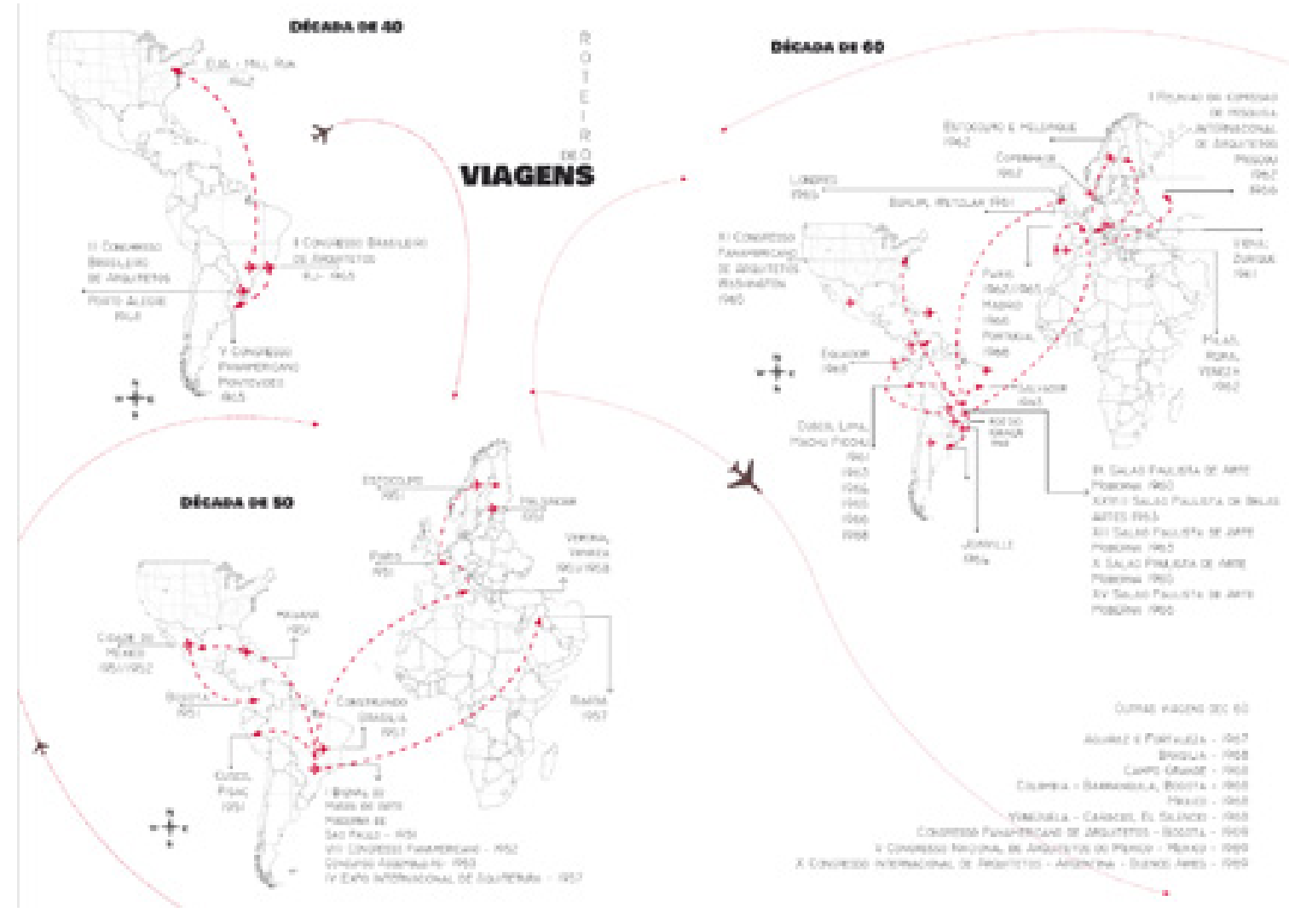
FIGURA 12

Países fotografados nas décadas de 1970 1980 e 1990, em

mapa-múndi. Mapa elaborado para a produção do trabalho. Fonte: Elisa Horta.
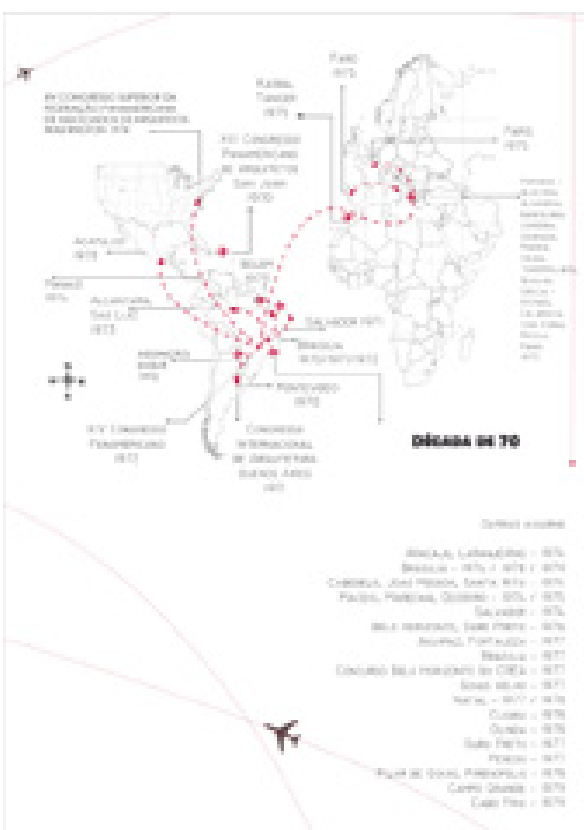

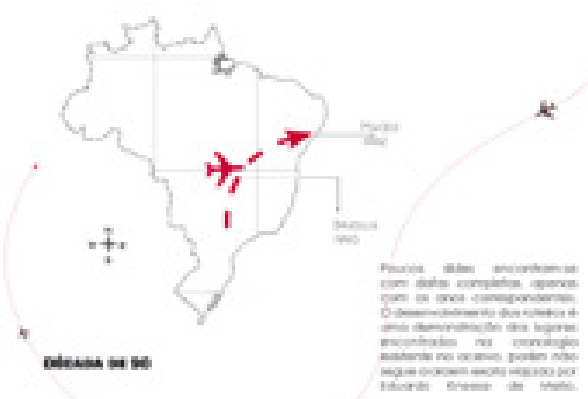

A este outro mapa couberam informações numéricas relativas à quantidade de slides por região, por meio de manchas de temperatura, graduados na cor vermelha, mais quente - maior quantidade - à azul, mais fria - em menor quantidade.

\footnotetext{
FIGURA 13

Quantificação dos slides em mapa-múndi. Mapa elaborado para a produção do trabalho. Fonte: Elisa

Horta.
}

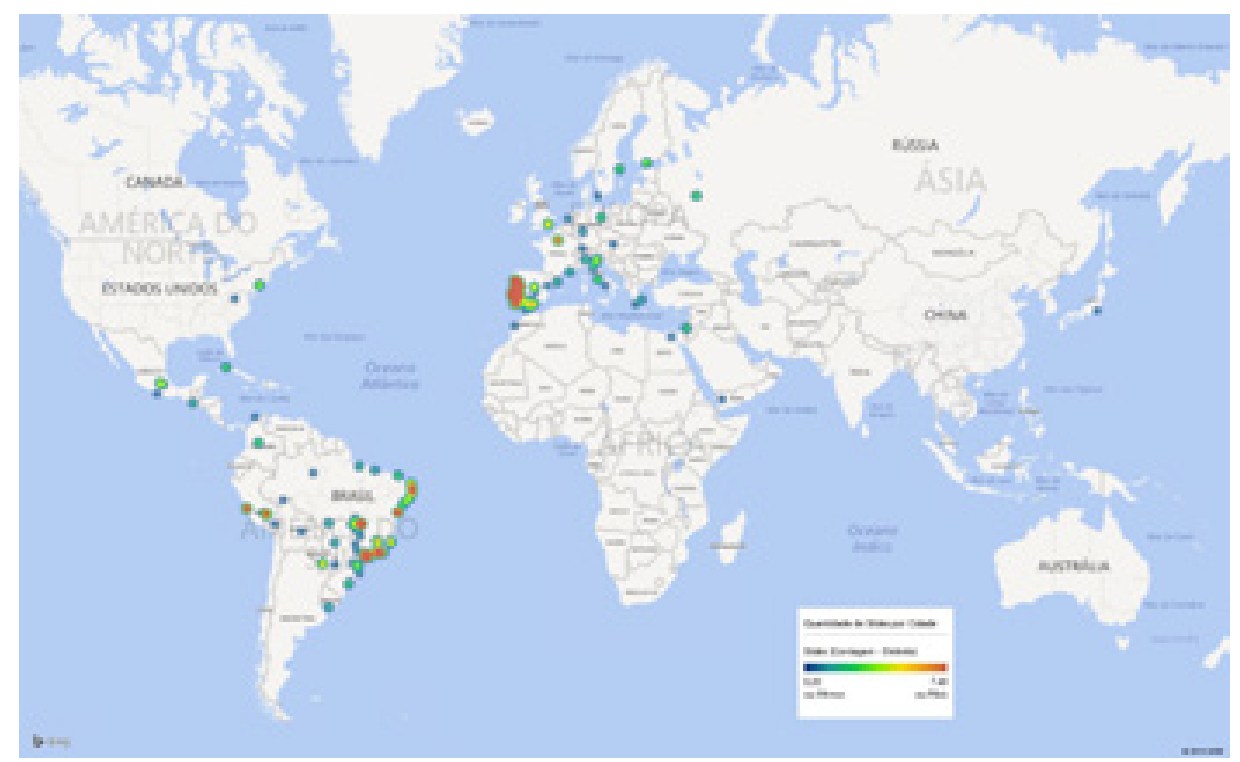




\section{POTENCIALIDADES}

Ainda que contando com toda a elaboração do catálogo do acervo, lacunas de informações pairam sobre ele e delineiam a elaboração de estratégias de dialéticas entre suas diferentes fontes documentais, sempre tratadas de maneira separada.

Kneese exercia atividades diplomáticas - militante da divulgação dos ideários do Movimento Moderno - em suas viagens, palestras e participações em congressos como representante do Instituto do Patrimônio Histórico e Artístico Nacional (Iphan) e do Conselho Regional de Engenharia e Agronomia (CREA), e como presidente ou delegado do Instituto de Arquitetos Brasileiros do Departamento de São Paulo (IAB-SP) e do Instituto de Estudos Brasileiros da Universidade de São Paulo (IEB). A confirmação dos dados já publicados deu-se a partir da leitura de cartas de agradecimento de políticos pela disponibilidade do arquiteto em se deslocar até a sua cidade e proferir tal palestra, ou ainda, convites de confederações internacionais para torná-lo membro de conselhos, para compor mesas de júri em concursos, certificados de participação em diversos eventos, além de títulos honorários recebidos pelo arquiteto. A faceta diplomática e institucional de Kneese de Mello está claramente representada por intermédio da documentação em papel.

Merecem ser enaltecidos, conjuntamente, sua influência na criação do departamento do Instituto de Arquitetos Brasileiros do Estado de São Paulo e na construção de seu edifício sede e seu entusiasmo na consolidação das atribuições profissionais de um arquiteto (a) e urbanista; a tentativa de enraizamento junto a amigos e seu pai, da UNISECO do Brasil - após uma viagem à Inglaterra, em 1951, para estudos sobre tecnologias do pré-fabricado -, uma empresa para produção de arquitetura industrial no Brasil, com ideias advindas de sua pesquisa; a reelaboração de seu estudo sobre as características da arquitetura brasileira, originárias da colonização portuguesa e de seus antepassados colonizadores árabes, publicado pela Faculdade de Arquitetura e Urbanismo da Universidade de São Paulo (FAU-USP), após estudo em Portugal, na década de 1960. Editado apenas em gênero textual, seu acervo conta com quase dois mil ícones, com potencial de investigação e reedição do livro em formato ilustrado.

Como professor de História da Arquitetura e do Urbanismo, atuou em universidades como a Farias Brito, atual Universidade Guarulhos (UNG) - para 
qual projetou o primeiro edifício dedicado unicamente ao curso de arquitetura-; a Universidade Presbiteriana Mackenzie, onde iniciou sua carreira como docente; a Universidade Braz Cubas, onde influenciou a implementação do curso de Arquitetura e Urbanismo, em 1970; a Faculdade de Arquitetura e Urbanismo da Universidade de São Paulo (FAU-USP); e no Centro Universitário Belas Artes de São Paulo, de 1987 até o ano de seu falecimento.

Seu legado como projetista, desde sua formação como seguidor do ecletismo a sua conversão à arquitetura moderna. Seu envolvimento com a construção de Brasília, tema muito presente no acervo, com 13\% do total de imagens do país, na participação no desenvolvimento do projeto NovaCAP ${ }^{2}$, em Brasília, iniciado no ano de 1956 junto à equipe de Oscar Niemeyer. Contribuição revelada em imagens do então presidente Juscelino Kubistchek e do grupo de arquitetos responsáveis pela obra; testemunhos fotográficos desde o início de suas fundações. Assim como sua presença no projeto de Niemeyer no Parque do Ibirapuera, em 1954.

[...] há poucos dias, vindo para prestar a aula inaugural em nossa Faculdade, o arquiteto J. Vilanova Artigas, informou-nos, consultado a respeito, que V. S. possue uma coleção realmente notável de fotografias coloridas sôbre Brasília, estando elas prontas para serem expostas, em painéis de fórmica. Tal fato se nos afigura como a grande oportunidade de realizarmos uma exposição de alto nível [...].

Todavia, o entendimento do acervo não pode se delimitar apenas a sua trajetória profissional, fazendo-se importante a criação de um arranjo pessoal. Cópias de cartas trocadas entre os familiares, poemas escritos por Kneese a sua esposa, principalmente os publicados no livro Joãosinho o oficibói (MELLO, 1988) em decorrência da comemoração de suas bodas de ouro, ajudam a estruturar uma imagem de Eduardo como pessoa. Até mesmo seus discursos escritos de palestras, que cabem ao seu lado profissional, alicerçam a ideia que se tem sobre como pensava e quem, de fato, era

2. NovaCAP: Companhia Urbanizadora da Nova Capital, empresa estatal do Distrito Federal brasileiro criada para a construção da nova capital federal do país.

3. Carta advinda de Alberto Xavier, presidente do departamento de cultura do Centro dos Estudantes Universitários de Arquitetura, em 1959, como convite à elaboração de uma exposição inédita sobre Brasília com o auxílio da coleção de slides sobre a construção da nova capital do país, em Porto Alegre. 
Eduardo Kneese de Mello. Mas ainda são poucos os adjetivos que podem ser afirmados. Tem-se para o caso a ideia da realização de entrevistas, o mais breve possível, com familiares e conhecidos para o recolhimento de testemunhos fundamentais ao arranjo.

Seguindo da ideia de contextualização sincronizada do exterior, e consequentemente de sua compreensão, outro arranjo principal caberia aqui: a compreensão da visão de Kneese sobre a história da arquitetura e do urbanismo do país, que estava sendo escrita e fundamentada, pela visão de seus contemporâneos, e de todos os acontecimentos correntes à época.

\section{CONSIDERAÇÕES FINAIS}

De maneira independente, porém, em alguns momentos, conjunta, o trabalho teve como fundamento a intenção de complementar toda a base bibliográfica já publicada sobre Eduardo Kneese de Mello e fundamental a esta pesquisa, difundindo-se com todos os dados já reconhecidos, salvando e reconhecendo méritos individuais.

Kneese de Mello foi um grande arquiteto e influenciou dezenas de congressos e conferências arquitetônicas, além de muitos estudantes com os quais teve contato. Criou relação de amizade com grandes arquitetos e nunca deixou de lado seus valores familiares. Cartas e declarações comprovam sua conectividade com a esposa e a preocupação que mantinha em enviar notícias aos filhos quando estava em viagem, assim como todo o reconhecimento que recebeu com todas as suas honrarias como membro vitalício em diversas instituições e associações. A finalização do trabalho vem para que sua trajetória seja evidenciada e sua carreira, merecidamente reconhecida.

De acordo com Meneses (1998, p. 90), “[...] a simples durabilidade do artefato, que em princípio costuma ultrapassar a vida de seus produtores e usuários originais, já o torna apto a expressar o passado de forma profunda e sensorialmente convincente". Ainda que os itens documentais pertençam a diversas esferas contextuais, a relação com o titular é inerente e necessita que seus contornos sejam reforçados. Este processo, seguido da extroversão adequada e eficiente dos resultados, permitirá a preservação da memória do arquiteto Eduardo Kneese de Mello. Pois, a cada documento investigado dentro do acervo, este trabalho se mostra mais urgente e imprescindível. 
$\mathrm{O}$ acervo ainda precisa de muitos aprofundamentos, e agora com deveres específicos, mas, a partir de todo o trabalho realizado sabe-se que os próximos manejos acontecerão sob melhores fundamentos e controles. A consulta e a escolha de futuros assuntos serão facilitadas, principalmente com o apontamento das potencialidades do acervo, da elucidação cronológica de seus trabalhos e da dimensão de seus maiores interesses.

O empenho veio então a identificar e preservar características originárias e a conscientizar, porventura, sobre a importância de seus laços conectivos, além de quantificar seus conteúdos iconográficos e servir como viabilizador para a preparação do editorial de financiamento e a concretização do acondicionamento ideal do acervo.

\section{REFERÊNCIAS}

BENJAMIN, Walter. Passagens. Belo Horizonte: Editora UFMG; São Paulo: Imprensa oficial, 2007.

LACERDA, Aline Lopes de. A fotografia nos arquivos: produção e sentido de documentos visuais. Hist. cienc. saude-Manguinhos, Rio de Janeiro, v. 19, n. 1, p. 283-302, Mar. 2012 . Disponível em: $<$ http://www.scielo.br/scielo.php?script=sci_arttext\&pid=S0104-59702012000100015\&lng=en\&nrm =iso $>$. Acesso em: 2017. http://dx.doi.org/10.159o/So104-59702012000100015.

MELLO, Eduardo Kneese de. Joãosinho o Oficibói. São Paulo: FEBASP, 1988.

MENESES, Ulpiano T. Bezerra de. Memória e Cultura Material: Documentos Pessoais no Espaço Público. Estudos Históricos, v. 21, p. 89-103, 1998.

REGINO, Aline Nassaralla. Eduardo Kneese de Mello: do eclético ao moderno. 2011. $606 \mathrm{f}$. Tese (Doutorado em Arquitetura e Urbanismo) - Faculdade de Arquitetura e Urbanismo da Universidade de São Paulo, São Paulo, 2011.

SANTOS, Ademir Pereira dos. Eduardo Kneese de Mello: o fotógrafo, o arquiteto e o professor. 10 f. 2010. Artigo para Programa de Iniciação Científica em Arquitetura e Urbanismo do Centro Universitário Belas Artes de São Paulo.

SANTOS, Janaina Francelino dos; AMARAL, Raphael Thomaz Sanches do. Eduardo Kneese de Mello: arquiteto e fotógrafo - Organização do acervo de diapositivos do MuBA. S/d. $6 \mathrm{f}$. Artigo para Programa de Iniciação Científica em Arquitetura e Urbanismo do Centro Universitário Belas Artes de São Paulo. S. l., s. d.

SANTOS, Ademir Pereira dos. Viagens, fotografia e arquitetura: Conexões a partir das imagens de Eduardo Kneese de Mello do MuBA. Revista Belas Artes, São Paulo, 2009. Disponível em: < http:// www.belasartes.br/revistabelasartes/?pagina=player\&slug=revista-ba-viagens-fotografia-arquitetura $>$. Acesso em: 2017.

\section{BIBLIOGRAFIA}

BARTHES, Roland. A câmara clara: nota sobre a fotografia. Tradução Júlio Castañon Guimarães. Rio de Janeiro: Nova Fronteira, 2015. 
CAMARGO, Luana Rodrigues de. Eduardo Kneese de Mello e Portugal: o estudo da Arquitetura Mourisca e as influências na Arquitetura Brasileira. 2006. 11 f. Artigo para o Programa de Iniciação Científica em Arquitetura e Urbanismo do Centro Universitário Belas Artes de São Paulo.

KOSSOY, Boris. Fotografia e história. São Paulo: Ática,1989.

MELLO, Eduardo Kneese de. Arquitetura brasileira: palestras e conferências. São Paulo: FAUUSP, 1975.

MELLO, Eduardo Kneese de. Memorial para efeito de apresentação ao concurso de professor titular da Faculdade de Arquitetura e Urbanismo da Universidade de São Paulo. Disciplina: Arquitetura no Brasil. São Paulo: s.n., 1975.

REGINO, Aline Nassaralla; SANTOS, Ademir Pereira dos; et. al. Arquitetura atribuição do arquiteto: homenagem ao centenário do arquiteto EKM (1906-1994). São Paulo: Centro Universitário Belas Artes de São Paulo, 2005.

REGINO, Aline Nassaralla. Eduardo Kneese de Mello arquiteto: análise de sua contribuição à habitação coletiva em São Paulo. 2006. 293 f. Dissertação (Mestrado em Arquitetura e Urbanismo) - Faculdade de Arquitetura e Urbanismo, Universidade Presbiteriana do Mackenzie, São Paulo, 2006.

\section{ACERVOS}

Acervo Eduardo Kneese de Mello - Biblioteca de Obras Raras, Paulo Antonio Cardim

Acervo pessoal de Aline Nassaralla Regino

Recebido em: 29/8/2016

Aprovado em: 6/7/2017 